\title{
Determinants and predictors of the cost of COPD in primary care: A Spanish perspective
}

\author{
Javier de Miguel Diez' \\ Pilar Carrasco Garrido² \\ Marta García Carballo² \\ Angel Gil de Miguel $^{2}$ \\ Javier Rejas Gutierrez ${ }^{3}$ \\ José M Bellón Cano ${ }^{4}$ \\ Valentín Hernández \\ Barrera $^{2}$ \\ Rodrigo Jimenez García ${ }^{2}$ \\ 'Department of Pneumology, \\ University Hospital Gregorio \\ Marañón, Madrid, Spain; ${ }^{2}$ School \\ of Health Sciences, Rey Juan Carlos \\ University, Alcorcón (Madrid), \\ Spain; ${ }^{3}$ Health Outcomes Research \\ Department Medical Unit, Pfizer \\ Spain, Alcobendas (Madrid), Spain; \\ ${ }^{4}$ Department of Preventive Medicine, \\ University Hospital Gregorio \\ Marañón, Madrid, Spain
}

\begin{abstract}
Objectives: 1) To estimate the annual cost of patients with stable chronic obstructive pulmonary disease (COPD) followed in primary care in Spain; 2) To analyze the possible cost predictor variables.
\end{abstract}

Patients and methods: A multicenter, epidemiological, observational, descriptive study. Sociodemographic data, severity of disease, associated comorbidity, treatment followed by patients, quality of life (SF-12 questionnaire), health care resource utilization in the previous 12 months and duration of working disability due to COPD were collected.

Results: A total of 10,711 patients ( $75.6 \%$ men; $24.4 \%$ women) with a mean age of $67.1 \pm 9.66$ years were evaluated. The mean forced expiratory volume in one second $\left(\mathrm{FEV}_{1}\right)$ value was $57.4 \pm 13.4 \%$. The total cost per patient per year was $€ 1,922.60 \pm 2,306.44$. The largest component of this cost was hospitalization ( $€ 788.72 \pm 1,766.65)$, followed by cost of drugs $(€ 492.87 \pm 412.15)$ and visits to emergency rooms (€134.32 \pm 195.44$)$. Linear regression analysis found associated heart disease, $\mathrm{FEV}_{1}$, physical component of quality of life, number of medical visits (primary care physician, pneumologist and emergency room), hospital admissions (frequency and duration of stay) and duration of working disability to be significant predictors of the total annual cost.

Conclusions: The total annual cost of a COPD patient followed in primary care in Spain was considered high in this study. The presence of associated heart disease, severity of airflow obstruction, physical component of quality of life, health care resource utilization and duration of work disability were found to be predictor of cost.

Keywords: COPD, primary care, costs, predictors, Spain

\section{Introduction}

Chronic obstructive pulmonary disease (COPD) is one of the most important respiratory problems we face today. It is the fourth leading cause of morbidity and mortality in the developed world (Pauwels et al 2001). In Spain, COPD affects 9.1\% of the general population between 40 and 69 years of age (Sobradillo et al 2000), and is responsible for approximately $10 \%-12 \%$ of primary care visits and $35 \%-40 \%$ of visits to a pneumologist. It also causes $35 \%$ of permanent work disabilities and $7 \%$ of hospital admissions (Pauwels et al 2001; Álvarez-Sala et al 2001). Because of the growing morbidity and mortality associated with this disease, it causes a high utilization of health care resources and a large economic burden to society. Thus, it has been reported that the expenses caused by this disease in Spain amount by $2 \%$ of the national health annual budget and $0.25 \%$ of the gross domestic product (Álvarez-Sala et al 2001). Furthermore, it is predicted that the impact of this disease will increase in coming years as a result of the rise in the life expectancy of the population, the increase in its prevalence and the emergence of new drugs and treatment modalities. Despite this, there are few studies in Spain that have quantified the costs of COPD (Grupo DAFNE 2000; García et al 2003; Miravitlles et al 2003; Izquierdo 2003; 
Izquierdo-Alonso 2004; Masa et al 2004; Sicras Mainar et al 2007), and they differ in the criteria used for sampling and for assessment of the resources consumed. As a result, they also differ in the findings obtained. In addition, most of these studies had a small sample size and included patients from different care levels.

The primary objective of this study was to estimate the annual cost generated by patients with stable COPD followed in primary care facilities in Spain. The secondary objective was to analyze the possible variables with ability to predict the cost of the disease.

\section{Materials and methods}

\section{Design and study population}

This analysis is part of the EPIDEPOC study, a multicenter, epidemiological, observational, descriptive study carried out in the primary care setting to estimate the use of health care resources and to assess the quality of life of patients with stable COPD (Carrasco Garrido et al 2006). The recruitment of patients and calculation of sample size corresponded to that performed in the EPIDEPOC study (Carrasco Garrido et al 2006). For calculation of sample size, a cluster design was used, considering 3 types of variables: health centers, physicians, and medical records. As the health centers were considered to be homogeneous and representative of the Spanish geographical population, the medical record was chosen as the unit of study and the prescriber as the cluster. A previous study in a large cohort of 1,510 primary care patients found that the average annual cost per patient varied widely, with an estimated standard deviation of $€ 3,407$ (Izquierdo 2003). Assuming a precision of $€ 90,5,505$ medical records needed to be evaluated. If the effect of the cluster design is also taken into account, ie, the loss of efficacy from the use of clusters, assuming a correlation of 0.3 and a cluster size of 5, a total of 2,422 prescribers and 12,111 medical records would be required.

Patients were selected consecutively by primary care physicians from all Spanish autonomous communities, whose distribution was weighted based on the population of each community. Patients were recruited during a period of 3 months (from January 1 to March 31, 2003). Subjects of both sexes, aged 40 years or older, and diagnosed with COPD at least 12 months before the start of the study, were included. The diagnosis of COPD was performed according to the criteria of the Spanish Society of Pneumology and Chest Surgery (SEPAR) and was based on demonstration by means of forced spirometry of a forced expiratory volume in 1 second $\left(\mathrm{FEV}_{1}\right)$ less than $80 \%$ of the predicted value and a
$\mathrm{FEV}_{1} /$ forced vital capacity $(\mathrm{FVC})$ ratio less than 0.7 after the bronchodilation test. The severity of the disease was classified into three levels based on the $\mathrm{FEV}_{1}$ value: mild $\left(\mathrm{FEV}_{1}\right.$ $60 \%-80 \%$ of predicted value), moderate $\left(\mathrm{FEV}_{1} 40 \%-59 \%\right.$ of predicted value) and severe $\left(\mathrm{FEV}_{1}\right.$ less than $40 \%$ of predicted value), in accordance with the SEPAR criteria (Barberà et al 2001). Patients with a neurological or psychiatric illness that would preclude their assessment during the study were excluded. Patients with an acute exacerbation of COPD in the previous month were also excluded. An acute exacerbation was considered to be the occurrence of an impairment of the clinical condition of the patient characterized by increased baseline dyspnea, purulent sputum, increased volume of sputum or any combination of these symptoms.

The study was approved by the Ethics Committee of the Alcorcón Hospital Foundation, and all patients gave their oral consent to participate in it.

\section{Assessment of patients}

A single visit was completed in which sociodemographic data, year of COPD diagnosis, severity of the disease, comorbidity, and utilization of health care resources in the previous 12 months was collected. All patients were administered the short form 12-item (SF-12) quality of life questionnaire, an abbreviated version of the SF-36 health questionnaire (Ware et al 1996). These 12 items explain more than $90 \%$ of the variance of the physical and mental component scores of the SF-36. The physical (PCS-12) and mental component summary (MCS-12) scores are then calculated, using a value of 50 with a standard deviation of 10 as the reference population. The SF-12 is scored from 0 to 100 with higher scores indicating better health status.

Direct costs were calculated from the information on the different procedures provided by the managements of Madrid Health Area 8 and the Alcorcón and Móstoles Hospitals. Indirect costs were calculated using the human capital method. This method is based on the assumption that the value of the lost production is equal to the wages associated with obtaining this production. In other words, a day missed from work implies a loss of production equal to the wages that would have been earned on that day. The information on employment and wages was obtained from the Spanish Statistical Office.

\section{Statistical analysis}

Statistical analysis of the data was carried out using the SPSS 12.0 for Windows statistical package (SPSS Inc., Chicago, IL). Qualitative variables were described by 
frequency and percentage and quantitative variables by mean, standard deviation, minimum and maximum. The Pearson $\chi^{2}$ test was used to analyze the relationship between qualitative variables. Student's t test for independent measurements was used to calculate the differences in the means of the two groups and the ANOVA test to study the differences between more than two groups of patients. Finally, a multiple linear regression analysis was performed using the total annual cost per COPD patient as the dependent variable. Variables significant in the bivariate analysis or deemed clinically relevant were included in the model. All statistical tests were two-tailed and a value of $p<0.05$ was considered significant.

\section{Results}

The number of physicians participating in the study was 2,377 , which allowed a total of 10,711 patients ( $75.6 \%$ men) to be recruited, with a mean age of $67.1 \pm 9.66$ years. Table 1 show the sociodemographic and clinical characteristics of the

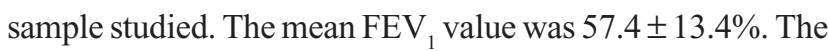
severity of the disease was mild in $35.5 \%$ of cases, moderate in $53.4 \%$ and severe in $11.2 \%$. The most frequent observed comorbidities were hypertension (47.7\%), hypercholesterolemia (41.3\%), anxiety $(22.2 \%)$, heart disease $(18.8 \%)$, gastroduodenal ulcer $(17.4 \%)$, diabetes $(16.9 \%)$, and depression (12.8\%). The mean PCS-12 and MCS-12 scores on the SF-12 quality of life questionnaire were $35.9 \pm 10.3$ and $48.2 \pm 11.4$, respectively. The mean number of drugs prescribed to the patients was $2.28 \pm 1.03$. The most frequently prescribed drugs were anti-cholinergics $(84.8 \%)$, followed by short-acting $\beta_{2}$-agonists (38.9\%), inhaled corticoids (22.1\%), theophyllines (11.8\%), long-acting $\beta_{2}$-agonists $(9.5 \%)$, mucolytics $(8.9 \%)$, and oral corticoids $(4.6 \%)$.

With regard to the use of health care resources in the previous year, the mean values were: visits to primary care physicians; $6.66 \pm 5.71$, visits to pneumologists; $1.43 \pm 1.52$, visits to emergency rooms; $1.60 \pm 2.71$ and hospital admissions; $0.50 \pm 1.17$ (Table 2). When the possible factors related to the use of health care resources were analyzed, a significant association was found with sex, with a significantly higher number of hospital admissions in men than in women $(0.53 \pm 1.24$ versus $0.33 \pm 0.93, p<0.001)$, although there were no differences in the number of visits to primary care or specialist physicians or in the duration of disability leaves. As expected, a statistically significant association was found between the use of health care resources and the age of the patients; the older the patient, the more frequent was the use of health care resources (Table 3 ). Finally, a clear association
Table I Sociodemographic and clinical characteristics of the patients studied

\begin{tabular}{|c|c|}
\hline \multicolumn{2}{|l|}{ Characteristic (no of patients) } \\
\hline Total no of patients & $107 \mid 1$ \\
\hline Age (years)* (8865) & $64.1 \pm 9.7(40 ; 98)$ \\
\hline \multicolumn{2}{|l|}{ Age groups (8862) } \\
\hline 40-54 years & $963(10.9)$ \\
\hline $55-64$ years & $2249(25.4)$ \\
\hline 65-74 years & $3669(41.4)$ \\
\hline$>75$ years & I98I (22.4) \\
\hline Sex (men) $(10,620)$ & $8030(75.6)$ \\
\hline \multicolumn{2}{|l|}{ Smoking $(10,649)$} \\
\hline Never smoked & $2468(23.2)$ \\
\hline Ex-smoker & $6153(57.8)$ \\
\hline Active smoker & $2028(19.0)$ \\
\hline $\mathrm{FEV}_{1}^{*}(9963)$ & $57.4 \pm 13.4$ \\
\hline \multicolumn{2}{|l|}{ COPD severity (9963) } \\
\hline Mild & $3634(35.5)$ \\
\hline Moderate & $547 \mid(53.4)$ \\
\hline Severe & $1146(11.2)$ \\
\hline \multicolumn{2}{|l|}{ Comorbidities } \\
\hline Hypertension (9876) & $4706(47.7)$ \\
\hline Diabetes (9453) & $1598(16.9)$ \\
\hline Heart disease $(9390)$ & $1770(18.8)$ \\
\hline Ulcer (9425) & $1637(17.4)$ \\
\hline Depression (9333) & $1196(12.8)$ \\
\hline Anxiety (9397) & $2084(19.5)$ \\
\hline \multicolumn{2}{|l|}{ Treatment } \\
\hline Short-acting $\beta_{2}$-adrenergic agonists $(10,706)$ & 4165 (38.9) \\
\hline Long-acting $\beta_{2}$-adrenergic agonists $(10,610)$ & $1008(9.5)$ \\
\hline Anticholinergics $(10,615)$ & $9002(84.8)$ \\
\hline Theophyllines $(10,703)$ & $1263(11.8)$ \\
\hline Inhaled corticoids $(10,7 \mid I)$ & $2369(22.1)$ \\
\hline Oral corticoids (I0,7II) & $498(4.6)$ \\
\hline Mucolytics $(10,674)$ & $950(8.9)$ \\
\hline Oxygen therapy $(10,007)$ & I35| (|3.5) \\
\hline
\end{tabular}

Notes: *Values expressed as mean \pm standard deviation (minimum; maximum) or frequencies (percentages).

Abbreviations: COPD, chronic obstructive pulmonary disease; FEV , forced expiratory volume in one second.

was found between the use of health care resources and the severity of COPD: patients with a more severe disease consumed more health care resources in terms of the number of visits to primary care, pneumologist and emergency rooms, the number of hospital admissions and duration of work disability (Table 4).

The total annual cost per COPD patient was $€ 1,922.60 \pm 2,306.44$, with the largest component for 
Table 2 Health care resource utilization and disability days at work during the year previous to the study

\begin{tabular}{|c|c|c|c|c|c|}
\hline $\begin{array}{l}\text { Health care resources and disability } \\
\text { at work }\end{array}$ & $\mathbf{N}$ & Median & Mean & $95 \% \mathrm{Cl}$ & \\
\hline Primary care physician visits (\#) & 10,242 & 5 & 6.66 & 6.55 & 6.77 \\
\hline Pneumologist visits (\#) & 9897 & I & 1.43 & 1.40 & 1.46 \\
\hline Emergency room visits (\#) & 9574 & 1 & 1.60 & 1.54 & 1.65 \\
\hline Hospital admissions (\#) & 8677 & 0 & 0.50 & 0.48 & 0.52 \\
\hline Duration of stay (days) & 4744 & 5.6 & 7.24 & 6.91 & 7.57 \\
\hline Duration of disability leave (days) & 4984 & 5.1 & 8.86 & 8.21 & 9.52 \\
\hline
\end{tabular}

Abbreviation: $\mathrm{Cl}$, confidence interval.

hospital admissions ( $€ 788.72 \pm 1,766.65)$, followed by cost of drugs ( $€ 492.87 \pm 412.15)$ and cost of visits to emergency rooms ( $€ 134.32 \pm 195.44$, Figure 1). Significant higher total annual costs were found in men than in women (Table 5), and in smokers and ex-smokers than in nonsmoker subjects (Table 6). Age and severity of disease was also shown to be associated with total costs, with differences according to gender at different levels of age and severity of disease. In men, both factors were found to be independently significant without interaction. In women, only severity of COPD was found to be statistically significant (Figure 2). As expected, patients with hospital admissions showed higher total annual costs than subjects without admissions (Table 7).

Table 3 Health care resource utilization by age group

\begin{tabular}{|c|c|c|c|c|c|}
\hline & $\mathbf{N}$ & Median & Mean & $95 \% \mathrm{Cl}$ & $\mathbf{p}$ \\
\hline \multicolumn{6}{|c|}{ Primary care physicians visits (\#): } \\
\hline$-40-54$ years & 921 & 4.00 & 5.73 & $(5.42-6.03)$ & \multirow{4}{*}{$<0.001$} \\
\hline$-55-64$ years & 2180 & 5.00 & 6.44 & $(6.20-6.68)$ & \\
\hline$-65-74$ years & 3525 & 5.00 & 6.84 & $(6.64-7.02)$ & \\
\hline$->75$ years & 1900 & 6.00 & 7.35 & $(7.06-7.63)$ & \\
\hline \multicolumn{6}{|c|}{ Pneumologist visits (\#): } \\
\hline$-40-54$ years & 887 & 1.00 & 1.28 & $(1.18-1.36)$ & \multirow{4}{*}{$<0.001$} \\
\hline$-55-64$ years & 2106 & 1.00 & 1.39 & $(1.33-1.46)$ & \\
\hline$-65-74$ years & 3418 & 1.00 & 1.45 & $(1.4|-| .50)$ & \\
\hline$->75$ years & 1840 & 1.00 & 1.57 & $(1.48-1.65)$ & \\
\hline \multicolumn{6}{|c|}{ Emergency room visits (\#): } \\
\hline$-40-54$ years & 865 & 1.00 & 1.37 & $(1.20-1.54)$ & \multirow{4}{*}{$<0.001$} \\
\hline$-55-64$ years & 2039 & 1.00 & 1.59 & $(I .47-I .7 I)$ & \\
\hline$-65-74$ years & 3311 & 1.00 & 1.62 & $(I .53-\mid .7 I)$ & \\
\hline$->75$ years & 1783 & 1.00 & 1.79 & $(1.65-1.93)$ & \\
\hline \multicolumn{6}{|c|}{ Hospital admissions (\#): } \\
\hline$-40-54$ years & 769 & 0.00 & 0.30 & $(0.24-0.36)$ & \multirow{4}{*}{$<0.001$} \\
\hline$-55-64$ years & 1828 & 0.00 & 0.40 & $(0.36-0.44)$ & \\
\hline$-65-74$ years & 3007 & 0.00 & 0.52 & $(0.47-0.57)$ & \\
\hline$->75$ years & 1670 & 0.00 & 0.68 & $(0.62-0.74)$ & \\
\hline \multicolumn{6}{|c|}{ Duration of disability leave (days): } \\
\hline$-40-54$ years & 693 & 8.00 & 15.60 & $(13.40-17.81)$ & \multirow{4}{*}{$<0.001$} \\
\hline$-55-64$ years & 1391 & 7.00 & 16.44 & $(14.73-18.14)$ & \\
\hline$-65-74$ years & 1402 & 0.34 & 2.10 & $(1.62-2.58)$ & \\
\hline$->75$ years & 677 & 0.00 & 0.42 & $(0.22-0.62)$ & \\
\hline
\end{tabular}

Abbreviation: $\mathrm{Cl}$, confidence interval. 
Table 4 Health care resource utilization by COPD severity

\begin{tabular}{|c|c|c|c|c|c|}
\hline & $\mathbf{N}$ & Median & Mean & $95 \% \mathrm{Cl}$ & $\mathbf{P}$ \\
\hline \multicolumn{6}{|c|}{ Primary care physician visits (\#): } \\
\hline - Mild COPD & 3529 & 4.00 & 5.15 & $(5.00-5.30)$ & \multirow{3}{*}{$<0.001$} \\
\hline - Moderate COPD & 5246 & 6.00 & 7.08 & $(6.92-7.25)$ & \\
\hline - Severe COPD & 1096 & 7.50 & 9.54 & $(9.09-9.99)$ & \\
\hline \multicolumn{6}{|l|}{ Pneumologist visits (\#): } \\
\hline - Mild COPD & 3369 & 1.00 & 1.01 & $(0.97-1.04)$ & \multirow{3}{*}{$<0.001$} \\
\hline - Moderate COPD & 5090 & 1.00 & 1.52 & $(1.48-1.56)$ & \\
\hline - Severe COPD & 1084 & 2.00 & 2.32 & $(2.19-2.46)$ & \\
\hline \multicolumn{6}{|c|}{ Emergency room visits (\#): } \\
\hline - Mild COPD & 3255 & 0.00 & 1.01 & $(0.94-1.08)$ & \multirow{3}{*}{$<0.001$} \\
\hline - Moderate COPD & 4623 & 1.00 & 1.71 & $(1.63-1.79)$ & \\
\hline - Severe COPD & 1057 & 2.00 & 2.88 & $(2.68-3.08)$ & \\
\hline \multicolumn{6}{|c|}{ Hospital admissions (\#): } \\
\hline - Mild COPD & 2975 & 0.00 & 0.24 & $(0.20-0.28)$ & \multirow{3}{*}{$<0.001$} \\
\hline - Moderate COPD & 4406 & 0.00 & 0.50 & $(0.47-0.52)$ & \\
\hline - Severe COPD & 1001 & 1.00 & 1.33 & $(1.22-1.44)$ & \\
\hline \multicolumn{6}{|c|}{ Duration of disability leave (days): } \\
\hline - Mild COPD & 1967 & 4.38 & 7.22 & $(6.39-8.05)$ & \multirow{3}{*}{$<0.001$} \\
\hline - Moderate COPD & 2495 & 5.69 & 9.75 & $(8.77-10.73)$ & \\
\hline - Severe COPD & 348 & 4.48 & 11.02 & $(7.27-14.77)$ & \\
\hline
\end{tabular}

Abbreviations: $\mathrm{Cl}$, confidence interval; COPD, chronic obstructive pulmonary disease.

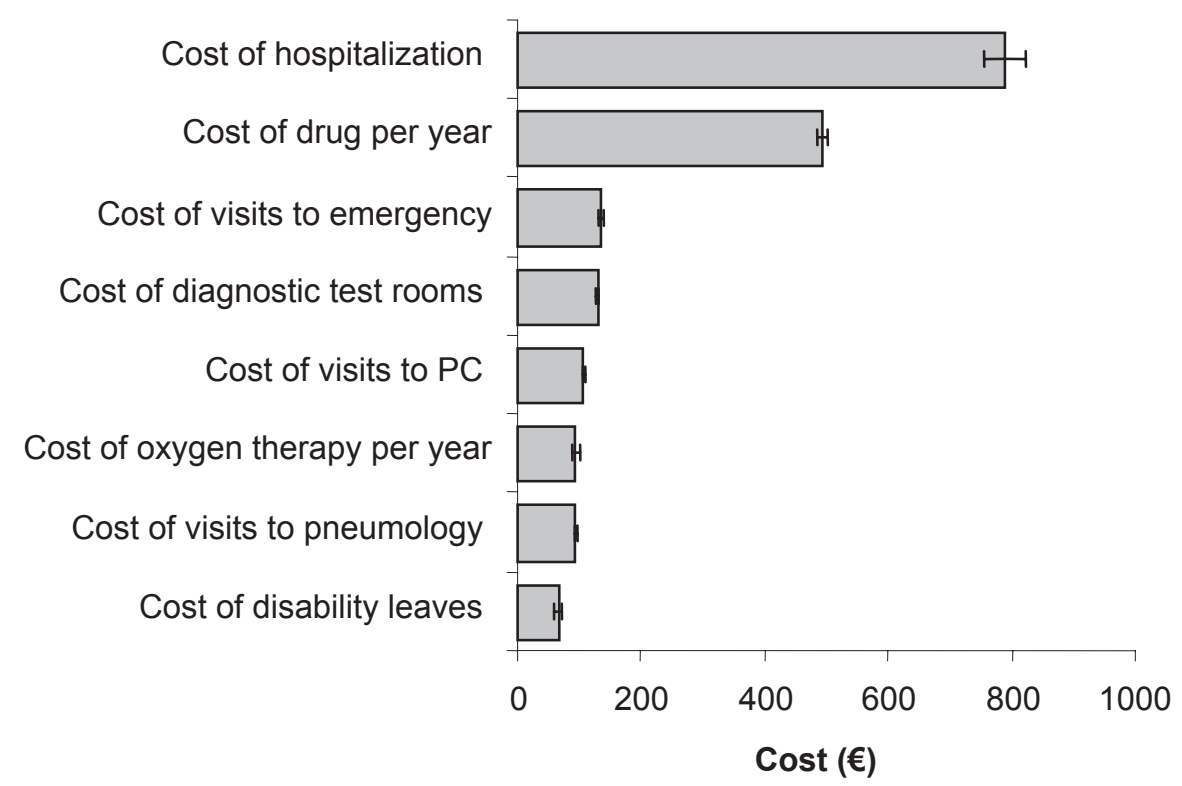

Figure I Comparison of different components of cost. 
Table 5 Comparison of different component of total costs by gender

\begin{tabular}{|c|c|c|c|c|c|}
\hline & Gender & $\mathbf{N}$ & Mean & Median & $95 \% \mathrm{Cl}$ \\
\hline \multirow[t]{2}{*}{ Cost of hospitalization } & Men & 8030 & $828.28 *$ & 563.75 & $(788.75-867.8 I)$ \\
\hline & Women & 2590 & 673.62 & 430.28 & $(610.77-736.47)$ \\
\hline \multirow[t]{2}{*}{ Cost of drugs per year } & Men & 8030 & $500.30 *$ & 529.25 & (491.24-509.36) \\
\hline & Women & 2590 & 467.13 & 365.00 & $(451.60-482.67)$ \\
\hline \multirow{2}{*}{$\begin{array}{l}\text { Cost of visits to emergency } \\
\text { rooms }\end{array}$} & Men & 8030 & $136.80 *$ & 104.52 & $(|32.49-| 4|| I)$. \\
\hline & Women & 2590 & 126.59 & 104.52 & $(119.30-133.88)$ \\
\hline \multirow[t]{2}{*}{ Cost of diagnostic tests } & Men & 8030 & |31.88* & 97.32 & $(|28.6|-\mid 35.16)$ \\
\hline & Women & 2590 & 120.35 & 97.32 & $(\mid 14.89-125.81)$ \\
\hline \multirow[t]{2}{*}{ Cost of visits to primary care } & Men & 8030 & 107.69 & 83.85 & $(105.57-109.81)$ \\
\hline & Women & 2590 & 104.37 & 83.85 & $(100.72-108.01)$ \\
\hline \multirow[t]{2}{*}{ Cost of oxygen therapy per year } & Men & 8030 & $101.87^{*}$ & 50.72 & $(95.17-108.59)$ \\
\hline & Women & 2590 & 68.20 & $15.4 \mid$ & $(58.32-78.09)$ \\
\hline \multirow[t]{2}{*}{ Cost of visits to pneumologists } & Men & 8030 & $95.58^{*}$ & 70.53 & $(93.21-97.95)$ \\
\hline & Women & 2590 & 87.22 & 70.53 & (83.26-91.18) \\
\hline \multirow[t]{2}{*}{ Cost of disability leave } & Men & 8030 & 69.02 & 21.90 & $(62.67-75.38)$ \\
\hline & Women & 2590 & 60.18 & 19.22 & $(50.33-70.03)$ \\
\hline \multirow[t]{2}{*}{ Cost of pneumococcal vaccine } & Men & 8030 & 4.65 & 4.36 & $(4.50-4.80)$ \\
\hline & Women & 2590 & 4.38 & 4.05 & $(4.12-4.64)$ \\
\hline \multirow[t]{2}{*}{ Cost of influenza vaccine } & Men & 8030 & $0.20 *$ & 0.00 & $(0.18-0.21)$ \\
\hline & Women & 2590 & 0.23 & 0.00 & $(0.21-0.25)$ \\
\hline \multirow{2}{*}{$\begin{array}{l}\text { Total annual cost per COPD } \\
\text { patient }\end{array}$} & Men & 8030 & $1989.20 *$ & 1112.20 & (1937.48-2040.93) \\
\hline & Women & 2590 & 1724.53 & 984.23 & $(1643.35-1805.7 \mid)$ \\
\hline
\end{tabular}

Note: ${ }^{*} \mathrm{p}<0.05$ between sexes, differences between means not significant when not stated. Abbreviations: $\mathrm{Cl}$, confidence interval; $\mathrm{COPD}$, chronic obstructive pulmonary disease.

On the other hand, a significant association between total costs and quality of life, as assessed with SF-12 questionnaire, was found with physical and mental components of quality of life. Subjects with worse quality of life showed higher costs, independently of gender (Figure 3). This figure shows the impact of poorer quality of life on total costs by quartiles of physical and mental components according to sex: The mental component showed a significant interaction with sex.

Linear regression analysis found associated heart disease, $\mathrm{FEV}_{1}$, physical component of quality of life, number of medical visits (primary care physician, pneumologist and emergency room), hospital admissions (frequency and duration of stay) and duration of working disability to be significant predictors of the total annual cost (Table 8).

\section{Discussion}

This study showed that the total cost per COPD patient was near $€ 2,000$ per year when primary care physicians take care on these subjects. Concomitant heart disease, reduced
$\mathrm{FEV}_{1}$, poor physical component of quality of life, increased number of medical visits, hospital admissions and incapacitating days for work were found to be explanatory variables associated with increased costs. The strength of this study lies in the elevated number of patients with stable COPD recruited in primary care clinics in Spain, including patients with multiple comorbidities, which are usually excluded from clinical trials. The study thus reflects real-world data. It should be taken into account that most Spanish patients with COPD are treated by general practitioners and that the proportion of patients referred to specialists is lower than in other West European countries (Esteban et al 2003).

Previous studies have shown health care total annual cost per COPD patient to vary between $€ 1,100$ and $€ 3,400$, with a median cost of about $€ 2,000$, a figure that is similar to that obtained in our study (Garcia et al 2003; Izquierdo 2003; Miravitlles et al 2003; Izquierdo-Alongo et al 2004; Masa et al 2004). The distribution of costs found in this study also shows considerable agreement with data provided by other authors: approximately $40 \%$ of the cost is produced by the 
Table 6 Comparison of different component of costs by tobacco use

\begin{tabular}{|c|c|c|c|c|c|}
\hline & Tobacco user & $\mathbf{N}$ & Mean & Median & $95 \% \mathrm{Cl}$ \\
\hline \multirow[t]{2}{*}{ Cost of hospitalization } & No & 2468 & 654.79 & 419.15 & $(592.56-717.03)$ \\
\hline & Yes & 8181 & $827.73^{*}$ & 561.51 & (788.39-867.06) \\
\hline \multirow[t]{2}{*}{ Cost of drugs per year } & No & 2468 & 476.91 & 529.25 & $(460.85-492.98)$ \\
\hline & Yes & 8181 & $497.00 *$ & 529.25 & $(488.05-505.95)$ \\
\hline \multirow[t]{2}{*}{ Cost of visits to emergency rooms } & No & 2468 & 119.42 & 52.26 & $(|12.5|-126.34)$ \\
\hline & Yes & 8181 & $138.69 *$ & 104.52 & $(134.34-143.04)$ \\
\hline \multirow[t]{2}{*}{ Cost of diagnostic tests } & No & 2468 & 120.30 & 97.32 & $(|| 4.8 I-125.80)$ \\
\hline & Yes & $818 \mid$ & $131.54 *$ & 97.32 & $(\mid 28.29-134.79)$ \\
\hline \multirow[t]{2}{*}{ Cost of visits to primary care } & No & 2468 & 104.37 & 83.85 & $(100.55-108.18)$ \\
\hline & Yes & 8181 & 107.79* & 83.85 & $(105.70-109.88)$ \\
\hline \multirow[t]{2}{*}{ Cost of oxygen therapy per year } & No & 2468 & 71.04 & 18.67 & $(60.79-81.28)$ \\
\hline & Yes & $8|8|$ & $100.260^{*}$ & 48.87 & $(93.64-106.87)$ \\
\hline \multirow[t]{2}{*}{ Cost of visits to pneumology } & No & 2468 & 87.19 & 70.53 & $(83.21-91.17)$ \\
\hline & Yes & 8181 & $95.33^{*}$ & 70.53 & $(92.97-97.68)$ \\
\hline \multirow[t]{2}{*}{ Cost of disability leave } & No & 2468 & 41.07 & 6.04 & $(32.08-50.06)$ \\
\hline & Yes & 8181 & $74.48^{*}$ & 26.36 & $(68.06-80.89)$ \\
\hline \multirow[t]{2}{*}{ Cost of pneumococcal vaccine } & No & 2468 & 4.96 & 4.69 & $(4.68-5.23)$ \\
\hline & Yes & 8181 & $4.48 *$ & 4.17 & $(4.34-4.63)$ \\
\hline \multirow[t]{2}{*}{ Cost of influenza vaccine } & No & 2468 & 0.17 & 0.09 & $(0.15-0.19)$ \\
\hline & Yes & $8|8|$ & $0.22 *$ & 0.14 & $(0.21-0.23)$ \\
\hline \multirow[t]{2}{*}{ Total annual cost per COPD patient } & No & 2468 & 1693.64 & 966.82 & $(|6| 1.7|-| 775.57)$ \\
\hline & Yes & 8181 & 1990.09* & 1113.66 & (I938.84-204I.33) \\
\hline
\end{tabular}

Notes: *p $<0.05$ between tobacco users, differences between means not significant when not stated. Tobacco use: "Yes" includes current smokers and ex-smokers, "No" includes never smoked.

Abbreviations: $\mathrm{Cl}$, confidence interval; $\mathrm{COPD}$, chronic obstructive pulmonary disease.

hospitalization component, which represents the largest proportion of the cost. Second most important component in term of cost was drug costs, which in our study represented almost $26 \%$ of the total expenses, being this value lower than that obtained in other studies. These differences might be explained by the greater severity of the patients included in our study. Thus, it has been shown an interaction between severity of disease and components of cost; as the severity of the disease increases, not only does the cost increase, but the distribution of costs changes as could be expected to some extend. Hence, hospital stay costs increase with severity of disease, and at the same time drug costs are reduced. In this way, a recent study carried out in our setting showed that drug therapy accounted for $43 \%$ of total direct costs in mild COPD, but that this percentage decreased to $37.6 \%$ and $28.4 \%$ in moderate and severe stages, respectively (Izquierdo Alonso et al 2004).

The reduction of lung function in COPD patients is associated with a higher number of cardiovascular events and deaths from a cardiac cause, although the mechanisms responsible for this association are not well known.
A relationship between COPD and cardiovascular diseases, linked to a systemic inflammatory component, has been observed even in patients with mild or moderate obstruction (Villar Álvarez et al 2008). This study showed that the prevalence of heart disease associated with COPD was high $(18.8 \%)$, and that it was one of the major determinants of the overall cost of the disease. These results contrast with those obtained in a recent study with a similar prevalence of cardiovascular events, in which no differences were observed in the annual cost per patient according to the presence or absence of these events (Sicras Mainar et al 2007). The authors of this study noted that certain limitations of the study require caution when generalizing the results, such as the design of the study itself, possible variability between the different participating physicians and the coordination of care levels, which complicates measurement of cost-effective interventions. However, and whether or not is confirmed that a relationship exists between COPD and cardiovascular diseases, linked to the systemic inflammatory component present in these patients, not only would it lead to an important advance in knowledge of the disease, 
A

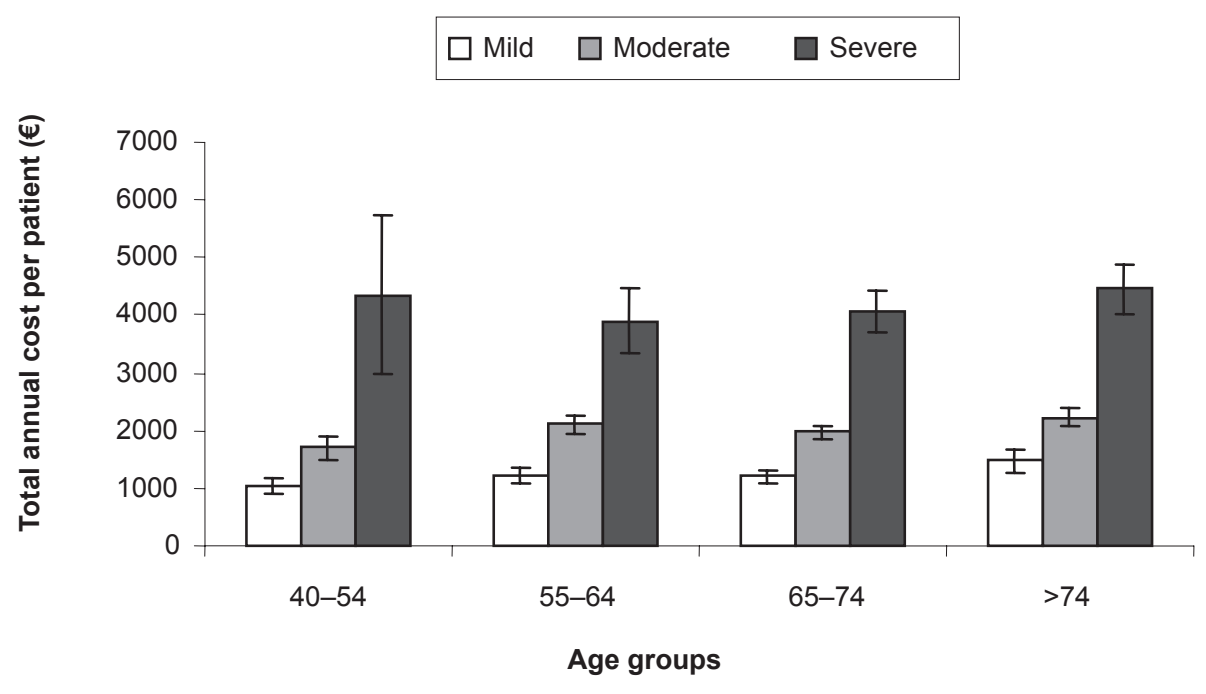

B

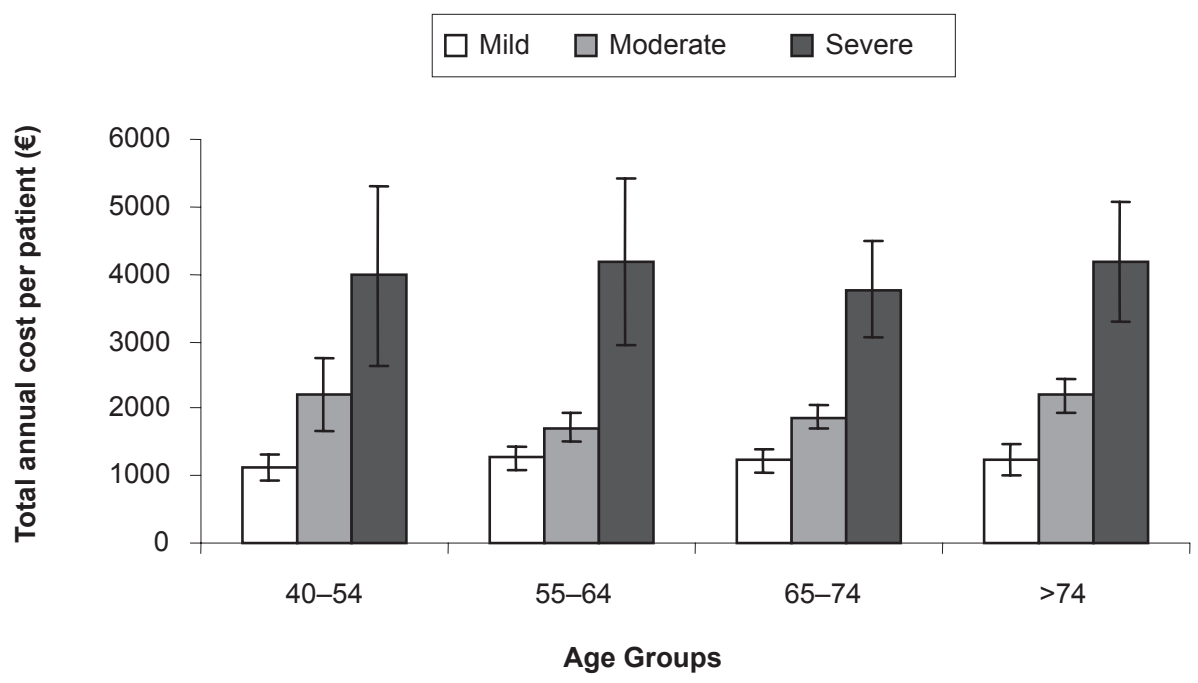

Figure 2 Analysis of cost by age and disease severity in men (A) and women (B).

but would allow new treatment strategies to be designed that should act on various inflammatory mediators, with the aim of modifying the risk of developing complications and reducing mortality (Sin et al 2003, 2005; Arroyo-Espliguero et al 2004).

The cost of management of COPD also depends, as was seen in this study, on the severity of airflow obstruction measured by $\mathrm{FEV}_{1}$. Along this same line, Hilleman and colleagues (2000) showed that the severity of COPD was strongly correlated with health care resource utilization and consequently with the total cost of the disease. The average direct cost per patient per year over a 5-year follow-up was US $\$ 1,681$ in ATS stage I (American Thoracic Society 1995), $\$ 5,037$ in stage II and $\$ 10,812$ in stage III. Subsequently, Masa and colleagues (2004) also found an increase in costs as the severity of the disease increased: the cost of 
Table 7 Comparison of different costs by hospitalization

\begin{tabular}{|c|c|c|c|c|c|}
\hline & $\begin{array}{l}\text { Hospital } \\
\text { admission }\end{array}$ & $\mathbf{N}$ & Mean & Median & $95 \% \mathrm{Cl}$ \\
\hline \multirow[t]{2}{*}{ Cost of hospitalization } & No & 6015 & 0.00 & 0.00 & $(0.00-0.00)$ \\
\hline & Yes & 2662 & $3173.56 *$ & 2010.00 & $(3088.66-3258.46)$ \\
\hline \multirow[t]{2}{*}{ Cost of drugs per year } & No & 6015 & 465.71 & 365.00 & $(455.80-475.6 I)$ \\
\hline & Yes & 2662 & $610.10^{*}$ & 529.25 & $(593.16-627.03)$ \\
\hline \multirow[t]{2}{*}{ Cost of visits to emergency rooms } & No & 6015 & 80.69 & 60.48 & (77.16-84.22) \\
\hline & Yes & 2662 & $291.49 *$ & 209.04 & $(282.24-300.74)$ \\
\hline \multirow[t]{2}{*}{ Cost of diagnostic tests } & No & 6015 & 98.87 & 97.32 & $(96.09-101.64)$ \\
\hline & Yes & 2662 & $224.17 *$ & 194.64 & $(216.69-231.66)$ \\
\hline \multirow[t]{2}{*}{ Cost of visits to primary care } & No & 6015 & 91.86 & 67.08 & (89.84-93.88) \\
\hline & Yes & 2662 & $158.70 *$ & 134.16 & $(154.17-163.23)$ \\
\hline \multirow[t]{2}{*}{ Cost of oxygen therapy per year } & No & 6015 & 36.45 & 0.00 & $(31.68-41.21)$ \\
\hline & Yes & 2662 & $261.56^{*}$ & 221.80 & $(244.47-278.65)$ \\
\hline \multirow[t]{2}{*}{ Cost of visits to pneumologists } & No & 6015 & 71.65 & 70.53 & $(69.64-73.66)$ \\
\hline & Yes & 2662 & $162.46 *$ & 141.06 & $(157.04-167.88)$ \\
\hline \multirow[t]{2}{*}{ Cost of disability leave } & No & 6015 & 49.84 & 16.30 & $(44.4 I-55.27)$ \\
\hline & Yes & 2662 & $105.47^{*}$ & 37.75 & $(90.65-120.28)$ \\
\hline \multirow[t]{2}{*}{ Cost of pneumococcal vaccine } & No & 6015 & 4.23 & 3.89 & $(4.07-4.40)$ \\
\hline & Yes & 2662 & $5.84 *$ & 5.67 & $(5.56-6.11)$ \\
\hline \multirow[t]{2}{*}{ Cost of influenza vaccine } & No & 6015 & 0.22 & 0.00 & $(0.21-0.24)$ \\
\hline & Yes & 2662 & $0.16^{*}$ & 0.00 & $(0.14-0.18)$ \\
\hline \multirow[t]{2}{*}{ Total annual cost per COPD patient } & No & 6015 & 911.90 & 816.23 & $(895.86-927.95)$ \\
\hline & Yes & 2662 & $5007.99 *$ & 4099.66 & (4099.66-5III.82) \\
\hline
\end{tabular}

Note: ${ }^{*} p<05$ between hospital admitted patients, differences between means not significant when not stated.

Abbreviations: $\mathrm{Cl}$, confidence interval; COPD, chronic obstructive pulmonary disease.

severe COPD was 7 times that of mild COPD and 3 times that of moderate COPD. Despite the above, a more recent study showed that although airflow obstruction is a valid predictor of health care resource utilization, its influence is small, and that the presence of comorbid conditions and symptoms of dyspnea are better predictors of costs (Mapel et al 2005).

Various authors have suggested the existence of other factors that may influence the cost of COPD (Miravitlles et al 2001; Soler et al 2001). One of these is health-related quality of life, which could explain why some COPD patients have a high utilization of health care resources and generate a high demand for these resources, as pointed out by Soler and colleagues (2001). Our study showed that the physical component of quality of life is one of the factors independently influencing the overall cost of COPD. Previous studies that assessed the health status of patients with this disease in Spain found a worse quality of life in those who had more dyspnea, a greater degree of obstruction, were treated with more drugs, suffered more exacerbations, and required more visits to emergency rooms and hospital admissions
(Miravitlles et al 2002, 2004; Sanjuás et al 2002; De Miguel et al 2004; Carrasco Garrido et al 2006).

Health care resource utilization is another of the major components of the cost of COPD, as shown in previous works (Mapel et al 2005). In this study, it was observed that among the factors determining the cost of COPD were the number of visits to the primary care physicians, the pneumologists and emergency rooms, as well as the number of hospital admissions and their duration. Therefore, strategies for management of COPD should emphasize measures to control chronic symptoms and reduce exacerbations and hospitalizations, because the largest part of the cost of this disease is related to hospitalization. Furthermore, a previous study analyzing the costs of hospitalization found that the cost of the stay accounted for $70 \%$ of the total cost of care of the hospitalized COPD patient, whereas the cost of medical care, examinations or the drugs used was less than a third of the total (Serra 2002). In this context, optimization of resources does not lie in controlling the number of complementary examinations, but in reducing the number of days of hospital stay (Escarrabil 2003). 
A

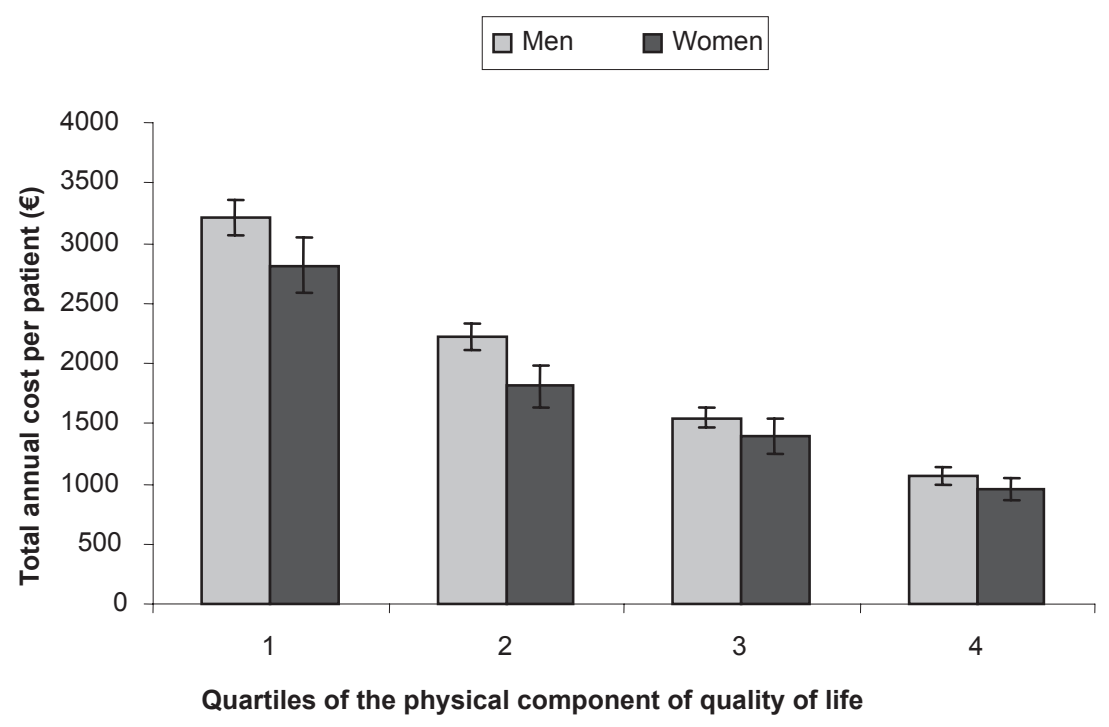

B

$\square$ Men $\square$ Women

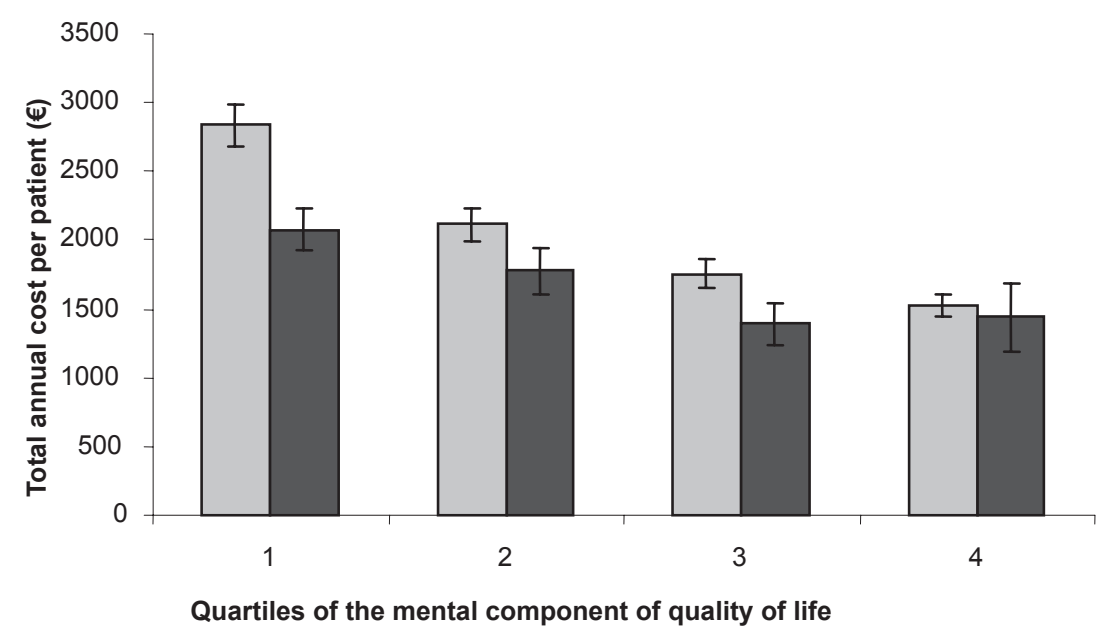

Figure 3 Cost by quartiles of the physical component (A) and the mental component (B) of quality of life by sex.

The indirect costs of COPD are more difficult to assess. There are few articles in Spain that have assessed this component and the results obtained varied widely, which has made their interpretation difficult (Krief 1996; Izquierdo 2003). It has been shown that patients with COPD have greater impairment of their ability to work and therefore are more likely to be disabled from work than those without this disease (Sin et al 2002). However, the estimated prevalence of work disability due to COPD remains controversial. Thus, Arancón (2002) indicated that asthma and COPD accounted for 3\% of permanent work disabilities in Spain in the period 1999-2000, a figure that rose to $5.3 \%$ in the group of patients between 50 and 64 years of age. However, this figure is very far from that estimated by the Spanish Society of Pneumology and Chest Surgery (SEPAR), which indicated that $35 \%$ of permanent work disabilities are due to COPD 
Table 8 Linear regression model to evaluate ability of variables to predict total costs

\begin{tabular}{|c|c|c|c|c|c|c|}
\hline Variable & B & $\begin{array}{l}\text { Standard } \\
\text { error }\end{array}$ & $\mathbf{T}$ & Significance & $95 \% \mathrm{Cl}$ & \\
\hline Heart disease & 227.9 & 72.4 & -3.1 & 0.002 & 85.8 & 369.9 \\
\hline Physical component (SF-I2) & -8.9 & 3.0 & -2.9 & 0.003 & -14.8 & -3.0 \\
\hline $\mathrm{FEV}_{1}$ & -10.6 & 2.2 & -4.8 & 0.000 & -14.9 & -6.3 \\
\hline No of visits to primary care & 22.8 & 5.2 & 4.3 & 0.000 & 12.6 & 33.0 \\
\hline No of visits to pneumology & 216.5 & 21.5 & 10.0 & 0.000 & 174.3 & 258.8 \\
\hline No of visits to emergency rooms & 180.5 & 14.4 & 12.4 & 0.000 & 152.1 & 209.0 \\
\hline No of hospital admissions & 1143.1 & 33.8 & 33.7 & 0.000 & 1076.6 & 1209.6 \\
\hline Duration of stay in days & 50.0 & 3.4 & 14.4 & 0.000 & 43.2 & 56.8 \\
\hline Duration of disability leave & 16.9 & 0.9 & 17.3 & 0.000 & 15.0 & 18.9 \\
\hline
\end{tabular}

Abbreviations: $\mathrm{Cl}$, confidence interval; COPD, chronic obstructive pulmonary disease; FEV , forced expiratory volume in one second; SF-12, short form I2-item quality of life questionnaire.

(Álvarez-Sala et al 2001; Pauwels et al 2001). Regardless of the actual prevalence, this study found that the duration of disability leaves was a factor that contributed independently to increasing the cost of this disease.

There are some limitations in our study. We excluded subjects with serious neurological and psychiatric diseases, and patients with recent exacerbations of COPD. As these disorders are expected to be associated with higher utilization of health care resources, we can not exclude an underestimation of the real cost of COPD. In spite of these limitations, the data presented along with the predicted increase in the health care cost of COPD in the future, both in terms of its direct and indirect costs (Pauwels et al 2001), underscore the need for developing strategies aimed to optimize the use of resources devoted to the management of COPD, with special attention to early diagnosis.

\section{Disclosure}

The authors report no conflicts of interest in this work.

\section{References}

Álvarez-Sala JL, Cimas E, Masa JF, et al. 2001. Recomendaciones para la atención al paciente con enfermedad pulmonar obstructiva crónica. Arch Bronconeumol, 37:269-78.

American Thoracic Society. 1995. Standards for the diagnosis and care of patients with chronic obstructive pulmonary disease. Am J Respir Crit Care Med, 152:S77-S120.

Arancón A. 2002. Estudio epidemiológico sobre la incapacidad permanente para el trabajo. Medicina General, 45:462-70.

Arroyo-Espliguero R, Avanzas P, Kaski JC. 2004. Enfermedad cardiovascular aterosclerótica: la utilidad de la proteína $\mathrm{C}$ reactiva en la identificación de la placa vulnerable y del paciente vulnerable. Rev Esp Cardiol, 57:375-8.

Barberà JA, Peces-Barba G, Agustí AGN, et al. 2001. Sociedad Espanola de Neumologia y Cirugia Toracica (SEPAR). Guía clínica para el diagnóstico y el tratamiento de la enfermedad pulmonar obstructiva crónica. Arch Bronconeumol, 37:297-316.
Carrasco Garrido P, de Miguel Díez J, Rejas Gutiérrez J, et al. 2006. Negative impact of chronic obstructive pulmonary disease on the health-related quality of life of patients. Results of the EPIDEPOC study. Health Qual Life Outcomes, 4:31.

De Miguel J, Izquierdo JL, Rodríguez JM, et al. 2004. Calidad de vida en la enfermedad pulmonar obstructiva crónica. Influencia del nivel de asistencia de los pacientes. Arch Bronconeumol, 40:431-7.

Escarrabil J. 2003. Costes sanitarios de la enfermedad pulmonar obstructiva crónica (EPOC). Arch Bronconeumol, 39:435-6.

Esteban C, Moraza J, Aburto M, et al. Description of a simple of patients with chronic obstructive pulmonary disease treated at hospital supervised respiratory clinics at primary care centres. Arch Bronconeumol, 39:485-90.

Garcia AJ, Leiva F, Martos F, et al. 2003. Utilización de recursos y costes directos sanitarios de la EPOC en atención primaria de salud (estudio EPOC-AP). Rev Esp Econ Salud, 2:176-81.

Grupo DAFNE. 2000. Costes directos de la bronquitis crónica en atención primaria. Análisis de un estudio prospectivo. Aten Primaria, 27:388-93.

Hilleman DE, Dewan N, Malesker M, et al. 2000. Pharmacoeconomic evaluation of COPD. Chest, 118:1278-85.

Izquierdo JL. 2003. The burden of COPD in Spain: results from the Confronting COPD survey. Respir Med, 97(Suppl C):S15-S22.

Izquierdo-Alonso JL, de Miguel-Díez J. 2004. Economic impact of pulmonary drugs on direct costs of stable chronic obstructive pulmonary disease. COPD, 1:215-23.

Krief B. 1996. (Gabinete de estudios sociológicos). Impacto social y económico de la EPOC en España. Farmacoeconomía, 8:8-19.

Mapel DW, McMillan GP, Frost FJ, et al. 2005. Predicting the costs of managing patients with chronic obstructive pulmonary disease. Respir Med, 99:1325-33.

Masa JF, Sobradillo V, Villasante C, et al. 2004. Costes de la EPOC en España. Estimación a partir de un estudio epidemiológico poblacional. Arch Bronconeumol, 40:72-9.

Miravitlles M, Figueras M. 2001. El coste de la enfermedad pulmonar obstructiva crónica en España. Opciones para una optimización de recursos. Arch Bronconeumol, 37:383-93.

Miravitlles M, Álvarez-Sala JL, Lamarca R, et al. 2002. Treatment and quality of life in patients with chronic obstructive pulmonary disease. Qual Life Res, 11:329-38.

Miravitlles M, Murio C, Guerrero T, et al. 2003. Costs of chronic bronchitis and COPD. A one year follow-up study. Chest, 123:784-91.

Miravitlles M, Ferrer M, Pont A, et al. 2004. Effect of exacerbations on quality of life in patients with chronic obstructive pulmonary disease: a 2 year follows up study. Thorax, 59:387-95. 
Pauwels RA, Buist AS, Calverley PMA, et al. 2001. Global strategy for the diagnosis, management and prevention of chronic obstructive pulmonary disease: NHLBI/WHO Global Initiative for Chronic Obstructive Lung Disease (GOLD) Workshop summary. Am J Respir Crit Care Med, 163:1256-76.

Sanjuás C. 2002. Disnea y calidad de vida en la enfermedad pulmonar obstructiva crónica. Arch Bronconeumol, 38:485-8.

Serra M. 2002. Aproximación a los costes por proceso en la EPOC. Actas del VIII Symposium sobre enfermedad pulmonar obstructiva crónica. March 14, 2002, Barcelona, Spain.

Sicras Mainar A, Navarro Artieda R, Fernández de Bobadilla J, et al. 2007. Estimación de la presencia de eventos cardiovasculares y costes directos asociados a la enfermedad pulmonar obstructiva crónica en un ámbito ambulatorio. Med Clin (Barc), 128:317-8.

Sin DD, Stafinski T, NG YC, et al. 2002. The impact of chronic obstructive pulmonary disease on work loss in the United States. Am J Respir Crit Care Med, 165:704-7.

Sin DD, Man SF. 2003. Why are patients with chronic obstructive pulmonary disease at increased risk of cardiovascular diseases? The potential role of systemic inflammation in chronic obstructive pulmonary disease. Circulation, 107:1514-9.
Sin DD, Man SF. 2005. Chronic obstructive pulmonary disease: a novel risk factor for cardiovascular disease. Can J Physiol Pharmacol, 83:8-13.

Sobradillo V, Miratvilles M, Gabriel R, et al. 2000. Geographic variations in prevalence and underdiagnosis of COPD. Results of the IBERPOC multicentre epidemiological study. Chest, 118:981-9.

Soler JJ, Sánchez L, Latorre M, et al. 2001. Impacto asistencial de la EPOC. Peso específico del paciente con EPOC de alto consumo sanitario. Arch Bronconeumol, 37:375-81.

Villar Álvarez F, de Miguel Díez J, Álvarez-Sala JL. 2008. Enfermedad pulmonar obstructiva crónica y acontecimientos cardiovasculares. Arch Bronconeumol, 44:152-9.

Ware JE, Kosinski M, Keller SD. 1996. A 12-item short-form health survey. Construction of scales and preliminary tests of realiabity and validity. Med Care, 34:220-33. 